\title{
Designing, processing and characterisation of titanium cylinders with graded porosity: An alternative to stress-shielding solutions
}

\author{
Y. Torres ${ }^{\mathrm{a}, *}$, P. Trueba ${ }^{a}, J_{\text {. Pavón }}^{\mathrm{b}, \mathrm{c}}$, I. Montealegre ${ }^{\mathrm{a}}$, J.A. Rodríguez-Ortiz ${ }^{\mathrm{a}}$ \\ ${ }^{a}$ Department of Engineering and Science of Materials and Transportation, University of Seville, Seville, Spain \\ ${ }^{\mathrm{b}}$ Group of Advanced Biomaterials and Regenerative Medicine, Bioengineering Programme, University of Antioquia, Medellín, Colombia \\ ${ }^{\mathrm{c}}$ Department of Nuclear, Plasma and Radiological Engineering, College of Engineering, University of Illinois at Urbana-Champaign, USA
}

\section{A R T I C L E I N F O}

\section{Article history:}

Received 25 March 2014

Accepted 4 June 2014

Available online 16 June 2014

\section{Keywords:}

Porous titanium

Powder metallurgy

Functionally graded material

Biomaterial

Stress shielding

\begin{abstract}
A B S T R A C T
Bone resorption events and consequent failure of titanium implants are frequently related to stress-shielding problems, due to stiffness mismatch with respect to bone. This is a mechanical incompatibility problem, which is difficult to resolve because of the challenge of replacing highly anisotropic biomechanical systems, as is the case of dental implants. This work describes the designing, processing and characterisation of cylindrical titanium samples with a longitudinally graded porosity obtained by conventional powder-metallurgy techniques. The design concept used was biomimetic, based on the stiffness properties of the tissues to be in contact with titanium dental implants. Processing conditions were optimised in terms of different parameters: structural integrity, porosity and mechanical properties. The influence of sintering temperature was evaluated in search of optimum results under the above criteria. The behaviour of longitudinal porosity and Young's modulus were consistent with the preliminary design concept from the original biomechanical system. Mechanical strength results were reasonably suitable for dental applications and they were favourably sensitive to increasing sintering temperature, due to a stronger adhesion between initial green layers of cylindrical samples. Results showed that it is possible to obtain a desired longitudinal gradient in Young's modulus, as well as suitable yield strength values. The optimised processing described suggests that it is a plausible candidate for manufacturing dental implants with a good balance between reduced stress shielding and suitable mechanical strength, which encourages us to undertake further work along the same lines.
\end{abstract}

(c) 2014 Elsevier Ltd. All rights reserved.

\section{Introduction}

Commercially pure titanium (cp Ti) and Ti-Al6-V4 alloy have been demonstrated to be the most biocompatible metallic biomaterials for bone replacement; this has been especially related to their surface properties, such as their passive oxide layer which makes them bio-inert, and their good mechanical properties for that biomechanical application [1]. These features have meant that the use of these materials for biomedical purposes has become a multibillion dollar market, with an important social and health impact worldwide [2]. Despite the recognised success of titanium implants, which has improved significantly during the last two decades with advances in osseointegration, they are still susceptible to improvements in their in vivo performance. Most research efforts have focused on surface and biointerface advances, and relatively few works have been dedicated to solving mechanical

\footnotetext{
* Corresponding author. Tel.: +34 954482 276; fax: +34 954460475 .

E-mail address: ytorres@us.es (Y. Torres).
}

mismatch problems with respect to bone. The high Young's modulus of titanium, implies that implants and prostheses avoid the transfer of an entire applied load to the bone, generating a stress-shielding phenomenon. As bone is a dynamic tissue, with its structure and density modulated by applied load, that mismatch between the Young's modulus of titanium and that of bone generates a loss of bone density, which is known as bone resorption. Many failures of titanium implants are associated with this phenomenon, generally manifested in fractures of surrounding bone, and subsequent loosening of the load bearing component of the prosthesis [3]. Therefore, it is desirable to design new implants and prostheses with lower stiffness than those currently available. This would allow resolving or reducing stress-shielding problems, without any important detrimental effect on mechanical strength. To that end, many research works can currently be found which are focused on the development of new implant materials with bonematching moduli; some of them relate to metastable $\beta$-titanium alloys [4], magnesium and its alloys [5] and porous materials [6-8]. The manufacturing processes of the latter are diverse, and 
the following may be highlighted: the electron beam melting process [9]; creep expansion of argon-filled pores [10]; directional aqueous freeze casting [11]; the rapid prototyping technique $[12,13]$; laser-engineered net shaping [14]; electric current activated/assisted sintering technique $[15,16]$; conventional powder metallurgy (PM) [17,18]; and space-holder technique [19-21]. Despite the important advances and insights obtained from the above works, it should be remembered that solving stressshielding problems becomes even more difficult when considering very specialised and anisotropic biomechanical systems; this is the case of materials and tissues that will be in contact with a dental implant [22]. A top-to-bottom analysis of titanium implants allows us to detect that they will be in contact with the stiffer material of the prosthetic crown $(E=100-200 \mathrm{GPa})$, then the very soft and compliant tissue of the gum, then cortical bone ( $E=20 \mathrm{GPa}$ [23]) and trabecular bone divided into two zones of different porosity ( $E=0.5-1 \mathrm{GPa}[23])$. Assuming that gum function is mainly as a seal, with a practically negligible mechanical support role, it is evident that the implant will suffer an anisotropic Young's modulus gradient with a strong decline from top to bottom (200 GPa down to $1 \mathrm{GPa}$ ). This fact will influence both the stress transfer to the bone and the structural integrity of the whole system. Therefore, it is rather interesting to design new implants with a graded porosity [24-26], that mimic the stiffness behaviour of the host biomechanical system, by considering the minimum mechanical strength for a successful application. This approach encompasses work [27] in which prosthetic parts with graded porosity were manufactured by using space-holder technique. This work showed the feasibility of processing parts, without mechanical testing or prior study of the processing and characterisation of the samples.

In line with the above, the aim of this work is to test the hypothesis that a conventional PM process is able to produce cylindrical titanium samples, with longitudinally graded porosity, that could be good candidates for solving the stress-shielding problem of dental Ti implants. Several optimisation steps and a complete microstructural and mechanical characterisation of the samples are included. Sample design corresponds to a bio-inspired framework in which the main criteria are the stiffness characteristics of the biomechanical system that would be in contact with a titanium dental implant. The authors chose the initial processing conditions based on their previous work on homogenous porous titanium by conventional PM [28] and loose-sintering technique [29]. An interesting study of the optimal mechanical pressure and sintering temperature was carried out in the same previous works, in order to determine the parameters which would allow a desired porosity to be obtained. The main starting point in the present work was to select a gradient design with four layers by applying different compaction pressures with a sintering temperature at $1000^{\circ} \mathrm{C}$. Afterwards, the optimal number of layers and sintering temperature were investigated by considering the criteria of structural integrity, the desired gradient of Young's modulus, and the mechanical strength represented by the yield strength. Cylindrical samples with graded porosity can be designed based on the stiffness anisotropy associated with materials and tissues in dental implantology.

\section{Materials and methods}

\subsection{Materials}

Commercially pure titanium (cp Ti) powder with a chemical composition equivalent to Grade 4 (ASTM: F67-13) was fabricated by a hydrogenation/dehydrogenation process in order to be used as the starting material. The particle size distribution, according to the supplier, presented a size lower than $9.7 \mu \mathrm{m}$ (D10), $23.3 \mu \mathrm{m}$ (D50), and $48.4 \mu \mathrm{m}$ (D90) (measured by a Matersizer 2000).

\subsection{Bio-inspired design criteria of porous samples with longitudinally graded porosity}

As mentioned above, a bio-inspired design concept was used to obtain cylindrical samples with a longitudinally graded porosity. In order to reduce the drastic stiffness change between the crown and the cortical bone, which would be in contact with a dental implant, it was initially decided to divide the cylindrical sample into four layers (discs); this first method was named route 1 . After the evaluation of these first results, several problems were detected and, consequently, adjustments of the manufacturing route were designed and performed to find solutions to these problems. These new routes were named route 2 , route 3 , route 4 and route 5 . All processing conditions are described in the following section.

\subsection{Processing of graded samples}

Graded samples were obtained by conventional PM and a loosesintering process. The conventional PM technique included mechanical compaction and sintering. An Instron 5505 universal machine (Instron, Norwood, MA, USA) was employed to apply the pressure needed to obtain the green compacts with a desired porosity. Prior to compaction, die-wall lubrication was performed to prevent cold welding between die and powder sample. The sintering process was performed in a Carbolite STF 15/75/450 ceramic furnace (Carbolite, Derbyshire, UK) with a horizontal tube for $2 \mathrm{~h}$, under high vacuum ( $\sim 10^{-5} \mathrm{mbar}$ ). The loose-sintering (LS) powder method is an interesting PM variant that includes a sintering step without previous compaction; this alternative technique to the conventional PM process is typically used to obtain samples with high porosities. The powders were set into an appropriately sized ceramic tube, into which was previously placed a multilayer green compact obtained by mechanical pressing, and then vibrated (eventually without vibration, LSWV). This step was completed in the same furnace used for sintering as mentioned above.

\subsubsection{Starting processing conditions}

The initial operational conditions were implemented in the route 1 . Under the four-layer design concept, two layers were axially compacted one by one, taking into account the Young's modulus of a current titanium dental implant $\left(E_{T i}=110 \mathrm{GPa}\right.$ [30]), and the corresponding Young's modulus of the tissues that would be in contact with it $\left(E_{\text {crown }}=100-150 \mathrm{GPa}\right.$; $E_{\text {bone }}=20 \mathrm{GPa}$ [23]). The first layer was consolidated at the highest compaction pressure, in order to achieve a Young's modulus close to a dental crown. Setting the first layer into the die, the second was compacted over the first. In this way, both layers were attached together and then ejected from the die and used as a substrate for layers 3 (LS) and 4 (LSWV). Such complete systems were put into the ceramic tube for the single sintering step.

A summary of the starting conditions and design of graded samples are presented in Table 1.

On the basis of the results, and to further optimise the process, several changes were made to the processing parameters, following evaluation of the structural integrity of the samples (visual inspection), porosity characterisation and mechanical testing. All the processing conditions are reported in the results section.

\subsection{Characterisation of the specimens}

\subsubsection{Structural integrity and interface quality}

Visual inspection of the samples allows preliminary information to be gathered about structural integrity and interface quality. To evaluate them, images of green compacts were captured after compaction and after sintering. Furthermore, macrographs were made of longitudinal sections at the end of the processing. A weighted 
Table 1

Processing conditions of 4-layer gradient design (routes 1, 2, and 3) and results. Ed is dynamic Young's modulus.

\begin{tabular}{|c|c|c|c|c|c|c|}
\hline \multirow[t]{2}{*}{ Layer } & \multirow[t]{2}{*}{ Design } & \multicolumn{2}{|c|}{ Processing conditions } & \multicolumn{3}{|l|}{ Results } \\
\hline & & Weight (g) & Pressure (MPa) & Sintering temperature $\left({ }^{\circ} \mathrm{C}\right)$ & Porosity (\%) & $\mathrm{Ed}(\mathrm{GPa})$ \\
\hline 4 & Highest porosity & 0.50 & LSWV & 1000 & 45.0 & 25 \\
\hline 3 & High porosity & 0.50 & LS & & 44.6 & 27 \\
\hline 2 & Medium porosity & 0.73 & 147 & & 19.8 & 70 \\
\hline 1 & Lowest porosity & 0.92 & 211.5 & & 15.6 & 80 \\
\hline
\end{tabular}

criterion was used to evaluate the results, grading structural integrity and interface quality on a scale of from 1 (very bad) to 5 (very good) interface. Firstly, structural integrity is based on the similarity to a perfect cylindrical sample without any cracks. Secondly, interface quality is related to the presence of cracks (macroscopically) or a very good adhesion between layers (microscopically).

\subsubsection{Porosity}

Density measurements of the whole sample were performed by Archimedes' method with distilled water impregnation because of its experimental simplicity and reasonable reliability (ASTM: C373-14). Total and interconnected porosity were calculated from density measurements. Moreover, porosity observations of each layer were captured by using a Nikon Epiphot optical microscope (Nikon, Tokyo, Japan) coupled with a Jenoptik Progres C3 camera (Jenoptik, Jena, Germany). Before this analysis, sectioned samples were suitably prepared by a sequence of conventional steps: resin mounting and grinding, followed by a mechano-chemical polishing with magnesium oxide and hydrogen peroxide. The main porosity characteristics estimated by this method were: (i) the pore shape factor, $F_{\mathrm{f}}=4 A / P_{E}^{2}$, where $A$ is the pore area and $P_{E}$ is the experimental perimeter of the pore; (ii) the mean free path between the pores, $\lambda$ (a measure of the mean size of the titanium matrix); (iii) the equivalent diameter, $D_{e q}$; (iv) the pore contiguity, $C_{p}$ (this parameter is a measure of the pore interconnectivity and it is calculated in the same way as cemented carbide [31], and $(v)$ the porosity itself.

\subsubsection{Mechanical testing}

A universal electromechanical Instron machine was used to run compression tests. The specimen dimensions were fixed to recommendations from standard ASTM: E9-09 (height/diameter $=0.8$ ) and strain rate was $0.005 \mathrm{~min}^{-1}$ [31-33]. All tests were stopped at a strain of $50 \%$. Afterwards, Young's modulus $(E)$, and yield strength $\left(\sigma_{y}\right)$, were estimated. Young's modulus calculations from compression stress-strain curves were corrected by including the stiffness of the testing machine $(87.9 \mathrm{kN} / \mathrm{mm})$. In addition, dynamic Young's modulus measurements by ultrasonic technique were performed by a Krautkramer USM 35 instrument (GE Measurement \& Control Solutions, Minden, NV), which was used to estimate both the longitudinal and transverse propagation velocity of acoustic waves. In order to evaluate longitudinal waves, a Panametric S-NDT probe of $4 \mathrm{MHz}$ was used and a Panametric S-V153 probe of $1 \mathrm{MHz} / .5$ was employed to measure cross-sectional waves. For nonporous cp Ti samples, velocities of longitudinal and cross-sectional waves were $6.1 \mathrm{~km} / \mathrm{s}$ and $3.12 \mathrm{~km} / \mathrm{s}$, respectively [34]. Once the acoustic wave velocities were measured,

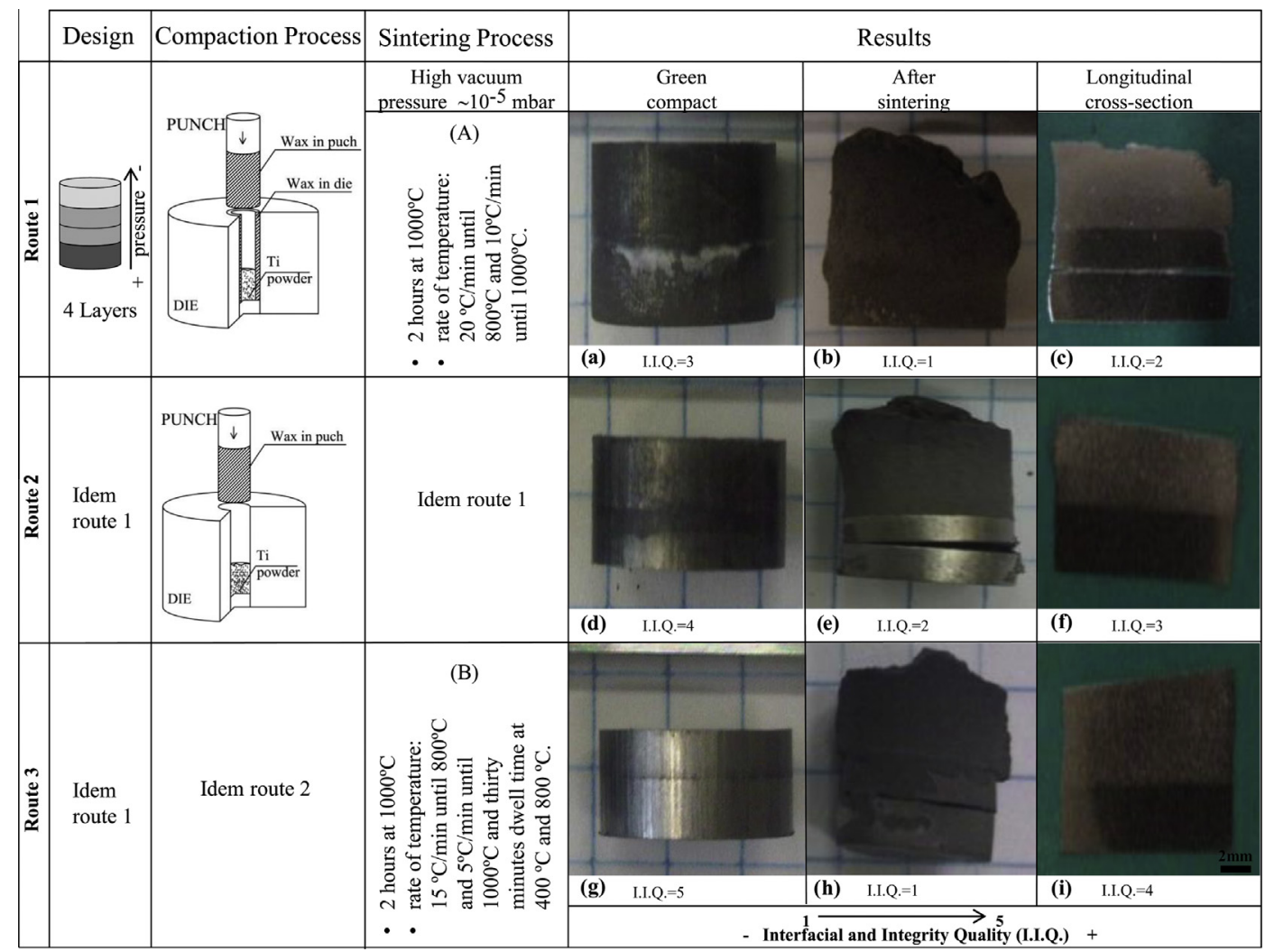

Fig. 1. Summary of gradient designs, compaction and sintering processing conditions, and results of the routes 1,2 and 3 . 
Table 2

Processing conditions of 6-layer gradient design (routes 4 and 5) and resultant porosity.

\begin{tabular}{|c|c|c|c|c|c|c|c|}
\hline \multirow[t]{3}{*}{ Layer } & \multirow[t]{3}{*}{ Design } & \multicolumn{3}{|l|}{ Route 4} & \multicolumn{3}{|l|}{ Route 5} \\
\hline & & \multicolumn{2}{|c|}{ Processing conditions } & \multirow{2}{*}{$\begin{array}{l}\text { Results } \\
\text { Porosity (\%) }\end{array}$} & \multicolumn{2}{|c|}{ Processing conditions } & \multirow{2}{*}{$\begin{array}{l}\text { Results } \\
\text { Porosity (\%) }\end{array}$} \\
\hline & & Pressure (MPa) & Sintering temperature $\left({ }^{\circ} \mathrm{C}\right)$ & & Pressure (MPa) & Sintering temperature $\left({ }^{\circ} \mathrm{C}\right)$ & \\
\hline 6 & Highest porosity & LSWV & 1000 & 45.0 & LSWV & 1100 & 43.0 \\
\hline 5 & High porosity & LS & & 44.6 & LS & & 41.0 \\
\hline 4 & Medium porosity & 73.5 & & 32.2 & 19.3 & & 31.4 \\
\hline 3 & Porosity & 147.4 & & 19.8 & 38.5 & & 21.8 \\
\hline 2 & Low porosity & 179.0 & & 17.7 & 64.1 & & 16.7 \\
\hline 1 & Lowest porosity & 211.5 & & 15.6 & 89.7 & & 11.5 \\
\hline
\end{tabular}

dynamic Young's modulus calculation was made by the use of an appropriate mathematical expression [35].

\section{Results and discussion}

\subsection{Structural integrity of graded samples (visual inspection criteria)}

\subsubsection{Route 1}

Fig. 1 shows the aspect of the samples obtained via route 1 (Table 1). The presence of wax between layer 1 and 2 in the green compacts is showed in Fig. 1a. Wax is normally used as a die-wall lubricant in the manufacture of homogeneous cylindrical samples by conventional PM. The lack of a minimum structural integrity and the gap between layers 1 and 2 of the sintered samples (Fig. 1b), can also be noted. A small amount of wax remains between layers and prevents a perfect cold joint between them in the green compact, which promotes a separation between layers during sintering (Fig. 1b and c). Therefore, die-wall lubrication was avoided for the next set of samples (route 2 ).

\subsubsection{Route 2}

This processing route was performed under the same conditions used in route 1 , excluding the step of using wax as a die-wall lubricant; only the punch that was used to press the samples was lubricated. The improvements, obtained by introducing the above modification, are represented in Fig. 1d-f. Remarkable advances were reached: in (i) total elimination of residual wax at the interfaces of green samples, as well as in (ii) improvement of structural integrity of the upper layers (LS and LSWV). However, the lack of integrity of the lower layers ( 1 and 2 ) is evident, indicating the need to explore other optimisation factors such as those which are sintering stage related.

\subsubsection{Route 3}

Two modifications in the sintering treatment were implemented in this route, in order to enhance the micro-movements between layers due to different shrinkages (Fig. 1b): (i) the rate of temperature of $15{ }^{\circ} \mathrm{C} / \mathrm{min}$ and $5{ }^{\circ} \mathrm{C} / \mathrm{min}$ instead of $20^{\circ} \mathrm{C} / \mathrm{min}$ and $10^{\circ} \mathrm{C} / \mathrm{min}$, respectively; and (ii) thirty-minutes-dwell time at $400{ }^{\circ} \mathrm{C}$ and $800^{\circ} \mathrm{C}$. Both changes provided more time for layer joining, reducing the different shrinkage between them. These improvement effects were even more effective between layers 3 and 4 (LS and LSWV) as can be seen in Fig. 1h. Therefore, another change had to be made to the design of the layers, in order to diminish shrinkage between them (route 4).

\subsubsection{Route 4}

The results obtained through route 3 led us to keep the same operation conditions, except for the number of layers to be pressed and the subsequent compaction pressures. To reduce abrupt change between porosity layers, their design was increased from four to six, with the inclusion of two intermediate compaction pressures (Table 2, route 4); in this context, the different shrinkage during sintering was reduced, as was the final effect on the interface quality. This hypothesis was supported by the fact that in all previous tests (routes 1,2 and 3), the top layers (interface 3-4)

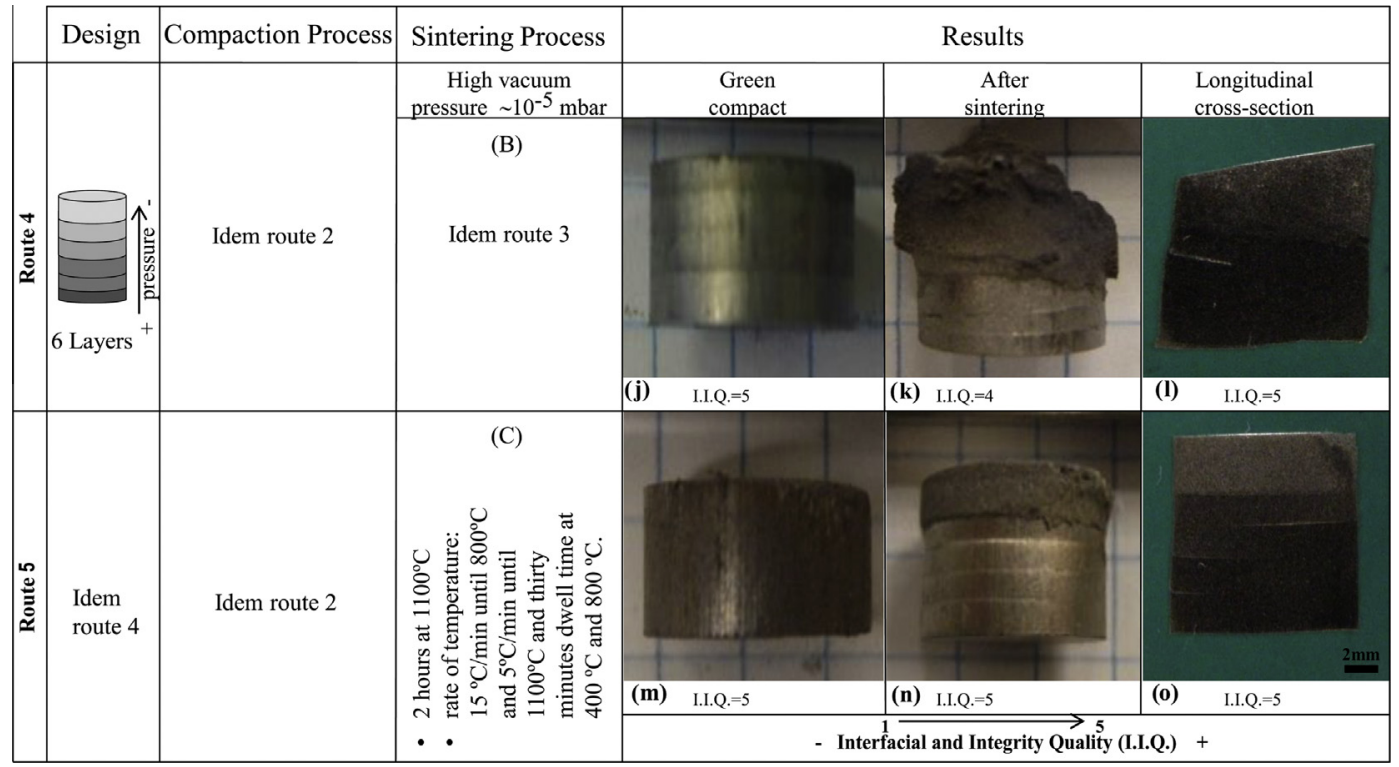

Fig. 2. Summary of gradient designs, compaction and sintering processing conditions, and results of the routes 4 and 5 . 

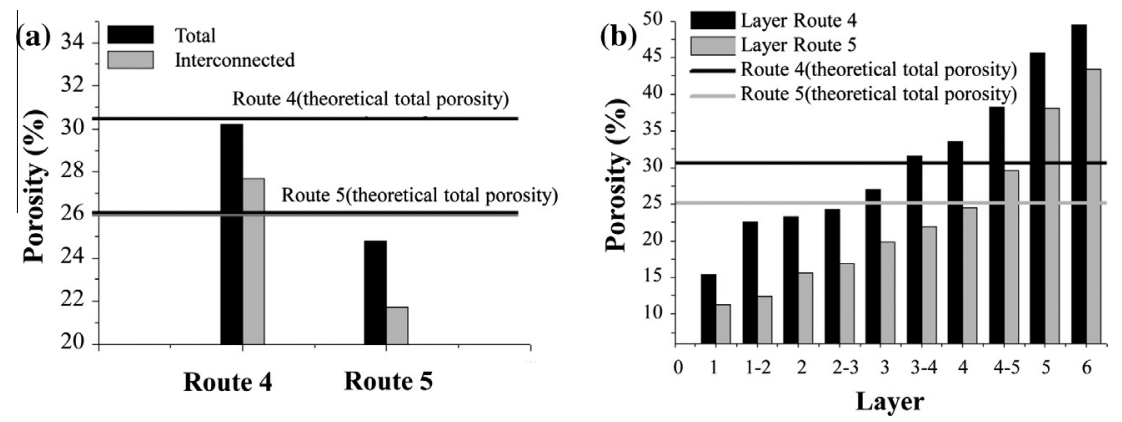

Fig. 3. Results of total and interconnected porosity in routes 4 and 5: (a) on the whole sample; (b) on each layer.

with least difference in compaction pressures between them, exhibited better integrity. Improvements due to the implementation of this new route can be observed in Fig. 2 j-l. A lower porosity gradient between layers of green samples effectively reduced sintering shrinkage between them. Therefore, the good structural integrity of both fabricated green (Fig. $2 \mathrm{j}$ ) and sintered samples (Fig. $2 \mathrm{k}$ and $\mathrm{l}$ ) demonstrates that reduction of compaction pressure between layers drastically enhances interface integrity.

\subsubsection{Route 5}

This route was the result of considering the same concept of intermediate pressures to improve interface integrity as in the case of route 4. Indeed, an increase of the sintering temperature was set in route $5,1000-1100^{\circ} \mathrm{C}$, to obtain a better interface quality between layers. Therefore, other compaction pressures were used for each layer. The compaction pressure was decreased to obtain a balance with reduced porosity due to increased temperature $\left(1100{ }^{\circ} \mathrm{C}\right)$; this helped to obtain similar porosity of the layers. This fact is related to the influence of that temperature increment from $1000{ }^{\circ} \mathrm{C}$ to $1100^{\circ} \mathrm{C}$, which is reflected in the processing conditions that appear in Table 2 , route 5 .

All structural integrity improvements observed in specimens sintered at $1000{ }^{\circ} \mathrm{C}$ through routes $2-4$, were also obtained in specimens produced at $1100{ }^{\circ} \mathrm{C}$ by route 5 . Furthermore, the interfaces of samples made by route 5 were significantly better than in samples produced in previous routes (Fig. $2 \mathrm{~m}-\mathrm{o}$ ).

\subsection{Comparative analysis of optimal routes}

The fabricated samples were characterised in order to make a detailed comparison of the significant differences between the routes 4 and 5 . In addition, the porosity and mechanical properties were studied.

\subsubsection{Porosity characterisation}

Some features can be highlighted from samples fabricated by route 4: (i) total porosity $(30.1 \%$, in Fig. 3 ) is reasonably close to the theoretical one (30.5\%); the latter is estimated from the expected porosity of each layer according to previous results [28-30] (Table 2), and by using a conventional mixing rule. This can be assumed as indicative of good methodology and processing feasibility; (ii) the porosity of the layers along the cylindrical samples presents a gradually increasing trend, which confirms the success of the graded design concept. Even by comparing individual porosity values of each layer there is an almost perfect match with respect to the theoretical (Fig. 3 b vs. Table 2, route 4); (iii) micrographs of longitudinal sections of samples confirm the graded porosity and show a clear lack of joining at the interfaces (Fig. 4, route 4). This latter defect is associated with the greater gradient of compaction pressures (138 MPa) between the layers, as well as with the lower sintering temperature $\left(1000^{\circ} \mathrm{C}\right)$. The influence of the gradient is evident from simple observation of the differences between the 4 and 5 interfaces (LS and LSWV) in comparison to the others. As was previously mentioned, the higher compaction pressure gradient, the higher the porosity difference, which implies a higher shrinkage difference during sintering.

The main finding on porosity measurements from route 5 samples is that the total porosity (24.9\%) is close to the theoretical (26.0\%) (Fig. 3). However, the difference between the theoretical and measured porosities is higher than that observed in route 4 . In addition to a logical reduced porosity $[28,29]$, the higher sintering temperature $\left(1100^{\circ} \mathrm{C}\right)$ used implies a higher shrinkage during sintering treatment in route 5 samples, as well as a better adhesion between interfaces with respect to route 4 . This improvement is

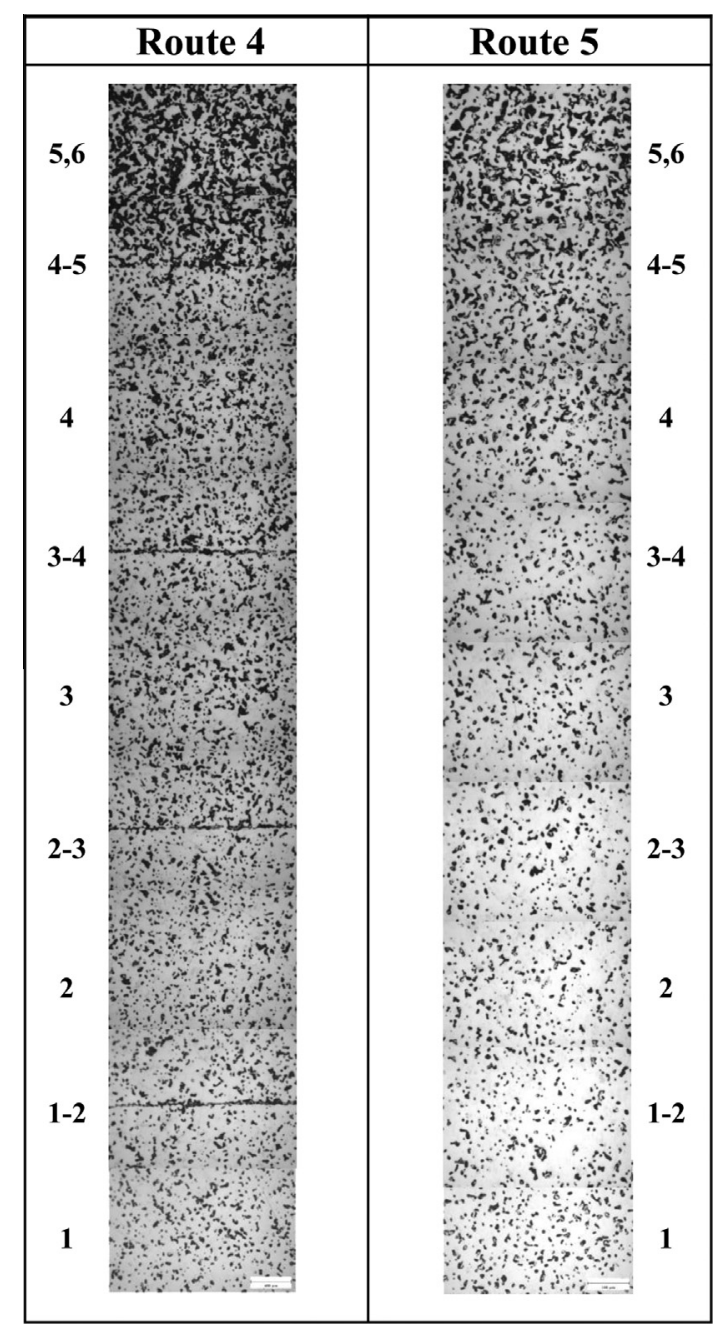

Fig. 4. Micrographs of longitudinal section of samples routes 4 and 5 . 
evident from the micrographs of the longitudinal section (see Fig. 4).

There was a significant improvement of the adhesion of layers as the fabrication routes were modified. This is a consequence of two facts: (i) the compaction pressure gradient between layers was clearly reduced in route 5 versus route 4 (layers 3-4, 19.25 MPa vs. 73.9 MPa; layers 2-3, 25.6 MPa vs. 31.6 MPa and layers 1-2, 25.6 MPa vs. 32.5 MPa, respectively). It means that a lower porosity gradient of the green compacts implies a lower shrinkage gradient between layers during sintering, obtaining stronger interfaces; (ii) a higher sintering temperature also means a higher global shrinkage during sintering, which also promotes improved post-sintering adhesion between layers (Fig. 4b). Obviously, these stronger interfaces obtained by route 5 are expected to have an important function in the mechanical response of these graded samples, as will be discussed in Section 3.2.2.

The porosity morphology parameters obtained in both processing routes are shown in Fig. 5: (i), in both routes, samples show that the equivalent diameter $\left(D_{e q}\right)$ increases as compaction pressure reduces along the graded cylindrical sample. Even more important is the gradual and continuous attenuation of this parameter, which verifies the gradient character of the samples; to some extent, this behaviour also validates both the design concept and the manufacturing process. It must be remarked that both processing routes present similar values of equivalent diameter for the highest pressures (layers 1-4), while values for the lowest pressures are clearly different. It indicates different sensitivity to sintering temperature because those layers (5 and 6) correspond to LS and LSWV in both kinds of sample. It should also be noted that the equivalent diameters of these two layers (LS and LSWV) are smaller than the others; however, shape factors $\left(F_{f}\right)$ are larger for route 5, suggesting that these layers will exhibit a better mechanical resistance than the others. Despite having a lower slope than the equivalent-diameter trend, the gradual trend of this parameter along the sample is also indicative of the effectiveness of the graded design. Note that route 5 samples $\left(1100^{\circ} \mathrm{C}\right)$ exhibit a practically constant pore shape factor, indicating a negligible sensitivity to the applied compaction pressures; however, for low-pressure layers, LS and LSWV, there is a clear decline; (ii) the pore shape factor of route 4 samples $\left(1000^{\circ} \mathrm{C}\right)$ is always higher than the pore shape factor of route $5\left(1100{ }^{\circ} \mathrm{C}\right)$, except for layers 5 and 6 , which have the highest porosity. This would mean that those layers of route 5 , being the most fragile, will have a better mechanical response than layers of route 4; (iii) in both processing routes, mean free path $(\lambda)$ increases with compaction pressure, and the gradient behaviour is more evident in the case of route 5 . In the case of route 4 , mean free path $(\lambda)$ is mainly constant, which is a sign of its poor sensitivity to the applied compaction pressure. From the mechanical point of view, route 4 samples would present a better response than those of route 5 ; that is expected because $\lambda$ values of route 4 samples were always higher than those of route 5 , except for layers 5 and 6 , in which cases that trend is inverted; (iv) pore contiguity $\left(C_{p}\right)$ shows an incremental behaviour with reducing compaction pressures for both processing routes; however, those increasing trends along the samples do not have a clear gradient-like behaviour. The most remarkable feature in Fig. 5 is that $C_{p}$ values (whole and layer by layer) of route 4 samples are clearly higher than those of route 5 , which is consistent with previous interconnected porosity measurements (see Fig. 3). In summary, the global behaviour of porosity morphology parameters allows a better mechanical strength to be expected from route $5\left(1100{ }^{\circ} \mathrm{C}\right)$ samples. This topic will be discussed in the following section.
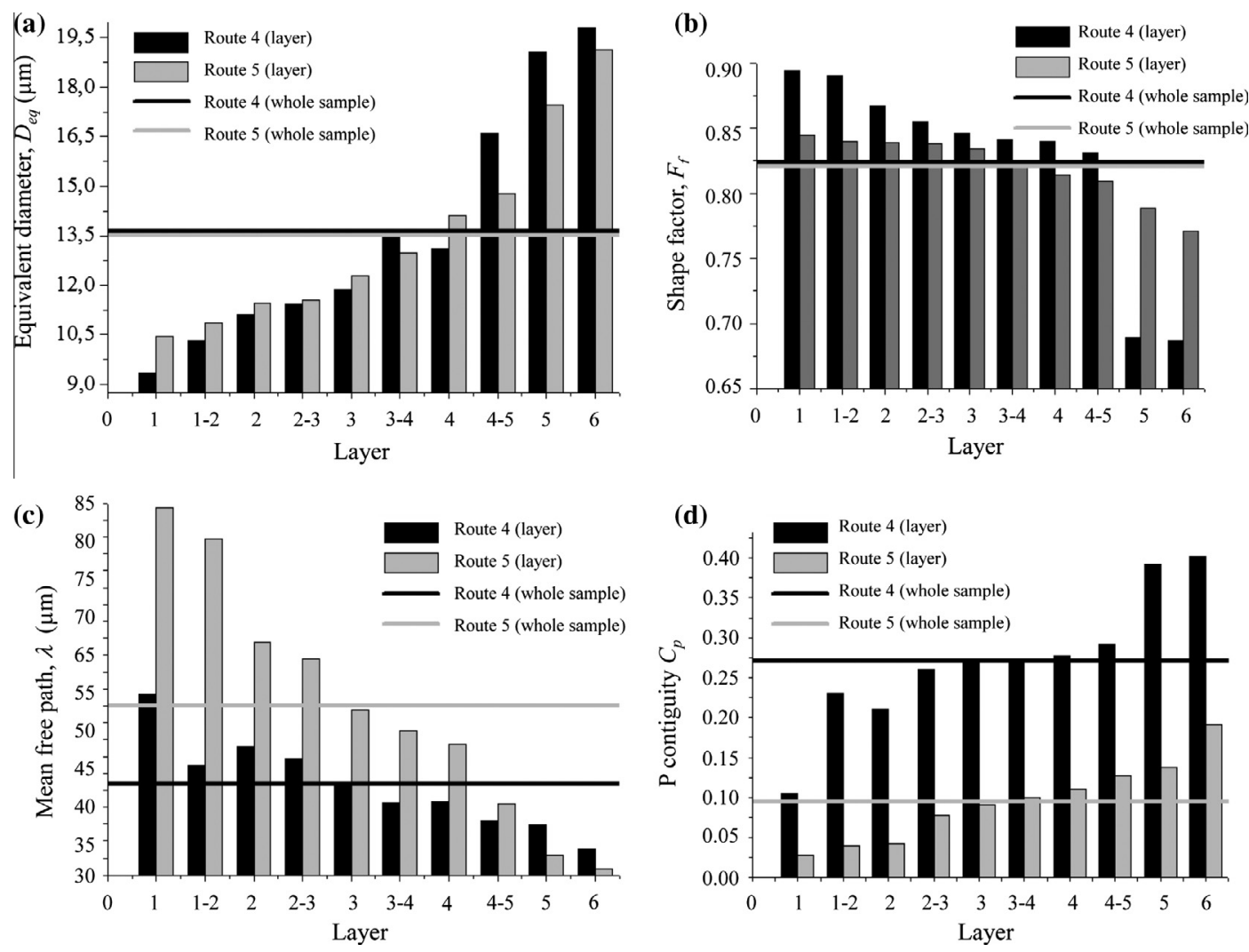

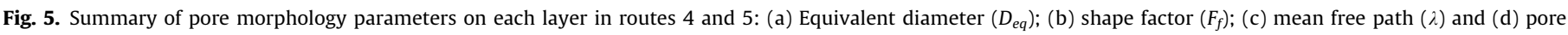
contiguity $\left(C_{p}\right)$. 

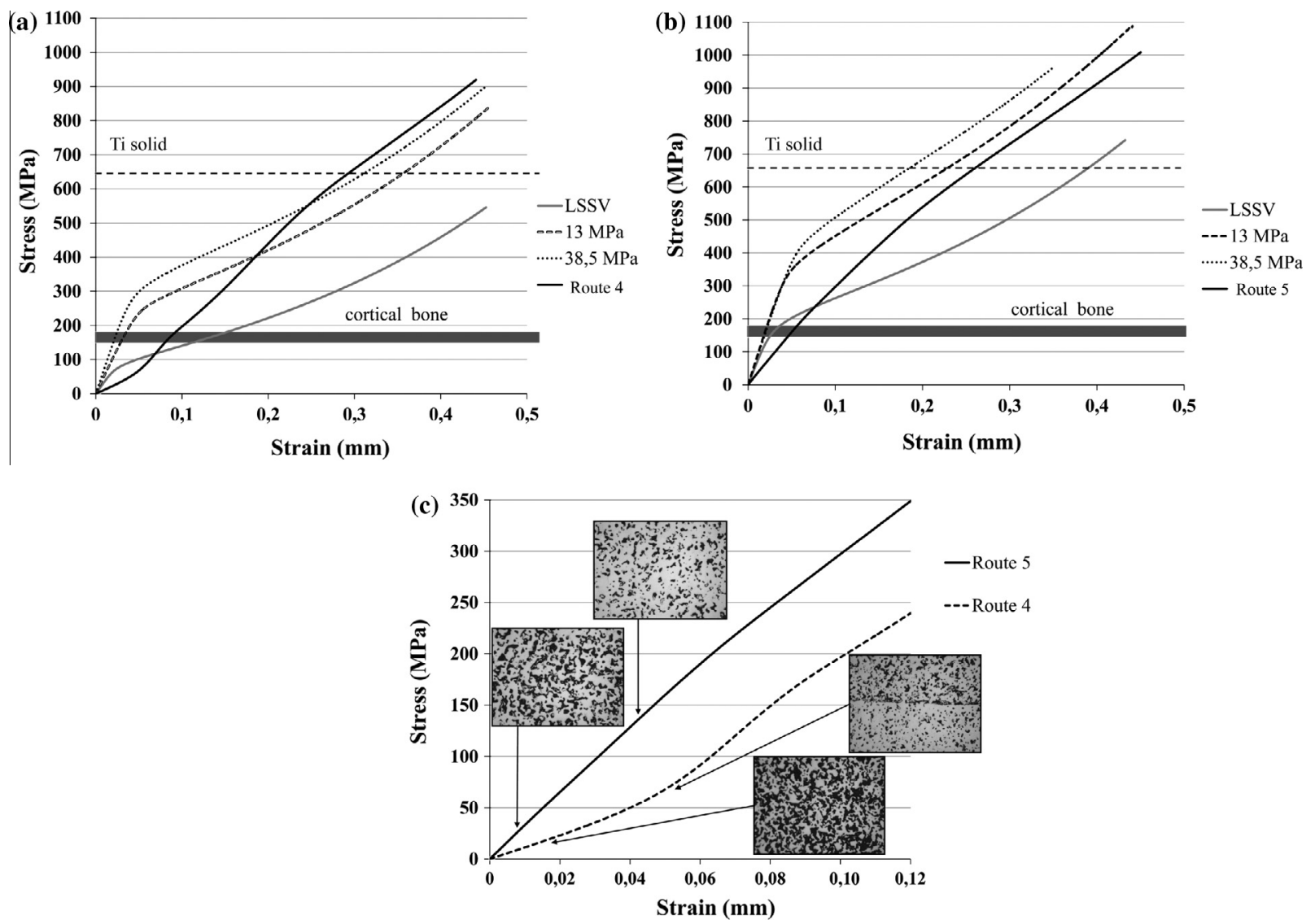

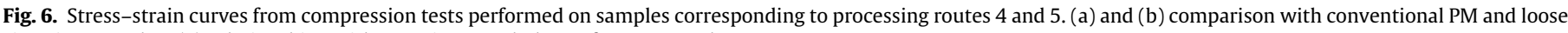
sintering samples; (c) relationships with porosity morphology of every sample.

\subsubsection{Mechanical testing}

Fig. 6 shows stress-strain curves from compression tests performed on samples corresponding to processing routes 4 $\left(100{ }^{\circ} \mathrm{C}\right)$, Fig. $6 \mathrm{a}$, and $5\left(1100^{\circ} \mathrm{C}\right)$, Fig. $6 \mathrm{~b}$. The mechanical behaviour of cylinders with graded porosity is compared with that obtained for compacts with homogeneous porosity [28,29], as well as the yield strength of cortical bone tissue and solid titanium. Moreover, Fig. 6c shows details of the stress-strain curves, and the relationship with the quality of the interfaces. The curve corresponding to route $4\left(1000^{\circ} \mathrm{C}\right)$ shows an initial non-continuous growth as stress is increased, associated with drops in load due to both a highest porosity and the lack of adhesion between initially separated interfaces; it exhibits a typical initial response of a highly porous solid. As a consequence, yield strength is very low with respect to both titanium monolith and cortical bone. In contrast, curves of route 5 appear with a better mechanical response and with a clear continuous growth. In that context, yield strength is clearly higher than route 4 samples and, what is even more important, is also higher than that of cortical bone. Despite the reasonably similar stiffness of both samples, there is an important difference in mechanical response, especially in yield strength. This different mechanical behaviour can be explained in terms of three different kinds of factors, which were previously analysed: total and interconnected porosity (whole and by individual layer), interface integrity and porosity morphology parameters $\left(D_{e q}, F_{f}\right.$, $\left.\lambda, C_{p}\right)$. From the porosity of the whole samples, it is evident that differences observed between samples from each processing route (Fig. 3) are certainly consistent with the stress-strain curves: both total and interconnected porosities of route $4\left(1000^{\circ} \mathrm{C}\right)$ samples are higher than those of route $5\left(1100^{\circ} \mathrm{C}\right)$, as well as the porosities measured layer by layer. These trends are directly related to the good mechanical response of route $5\left(1100^{\circ} \mathrm{C}\right)$ samples. From the interface structural integrity, a direct relationship with mechanical strength can be also stated: route 4 samples present interfaces with the worst adhesion (Fig. 4) and, therefore, they behave as important sample defects during compression tests. These defects are clearly reflected in both elastic and plastic responses in the stress-strain curves. Finally, porosity morphology parameters present the following relationships with the mechanical properties of each sample: (i) the equivalent diameter behaviour is consistent with the higher mechanical strength of route 5 samples (layers 1-4 similar values, layers 5-6 higher values of route 5); (ii) the pore shape factor is partially consistent with the mechanical response (layers $1-4$, route 4 is slightly higher; $5-6$, the most fragile, route 5 is higher); (iii) the mean free path $(\lambda)$ was higher for all sample layers from route 5 , except for layers 5-6; this can be also assumed to favour the highest mechanical strength of route 5 samples.

Regarding stiffness results from stress-strain curves, it must be noted that both kinds of samples present a similar elastic response. In order to obtain more reliable Young's modulus measurements, samples must be tested by using ultrasound technique, as was demonstrated by Torres et al. [28,32,34]. These measurements (Fig. 7) confirm that both kinds of samples exhibit similar Young's modulus values, which are reasonably close to that of cortical bone $\left(E_{r 5} \approx 38 \mathrm{GPa}, E_{r 4} \approx 36 \mathrm{GPa}, E_{c b} \approx 20 \mathrm{GPa}\right)$. Furthermore, indirect calculations of Young's modulus by using the Nielsen model (including experimental porosity parameters) confirm the graded character of samples regarding stiffness. It must be noted that Young's modulus behaviour along the samples has a direct relationship with the porosity percentage in each layer, whilst its agreement with porosity parameters is not so defined. This verifies the stronger sensitivity of Young's modulus to porosity percentage. 


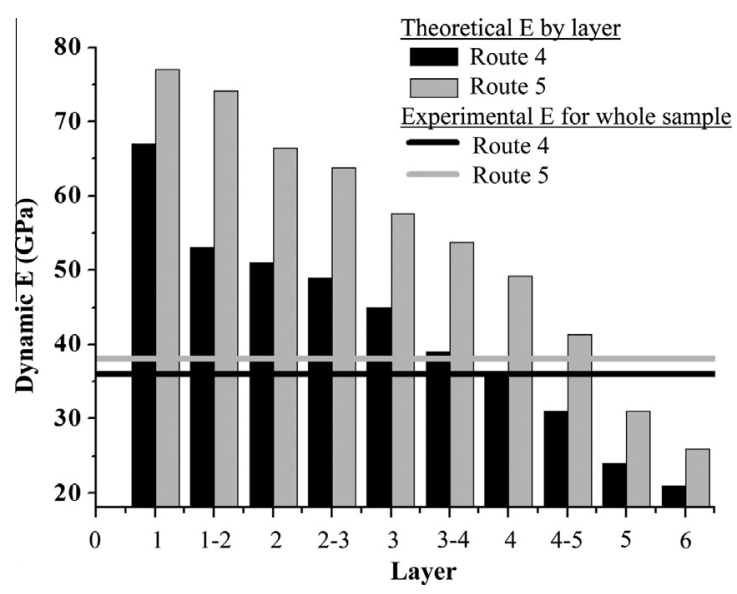

Fig. 7. Experimental Young's modulus evaluated by ultrasonic technique on whole sample versus theoretical Young's modulus on each layer using the Nielsen's model in routes 4 and 5 .

It is somewhat remarkable that the Young's modulus of route 4 samples, with the better mechanical strength, ranges from $75 \mathrm{GPa}$ (upper and stiffer layer, to be in contact with prosthetic crown in oral implantology) up to $24 \mathrm{GPa}$ (lower and more compliant layer, to be in contact with cortical bone).

Summarising the mechanical testing results, the following more important features can be emphasised: (i) the mechanical properties of both kinds of samples (route 4 and route 5) are so far well in agreement with microstructural and porosity features; (ii) the route 5 samples exhibit the best mechanical balance between a suitable yield strength and a reasonably low Young's modulus for the desired application; they also have an appropriate stiffness gradient between the elasticity of the prosthetic crown and the cortical bone, in order to be used in oral implantology.

\section{Conclusions}

Once the PM processing of cylindrical samples with a longitudinal porosity gradient by PM, with a stiffness gradient between that of a prosthetic crown and that of cortical bone, was optimised and characterized, the following findings can be summarised:

(1) The structural integrity and repeatability of samples was clearly sensitive to die lubrication, compaction pressure gradient between layers and sintering temperature.

(2) The best gradient corresponded to a 6-layer system (route 5) with a low pressure gradient between them, for a sintering temperature of $1100^{\circ} \mathrm{C}$ with a balance between a high mechanical strength, a low whole stiffness, and the best stiffness gradient.

(3) Consistency of design criteria of the porosity and the elasticplastic behaviour of tested samples (bulk and layer-by-layer) has exhibited a good agreement with all porosity and microstructural features. Elastic response was more sensitive to porosity percentage, whilst yield strength is consistent with porosity morphology parameters, and it is strongly sensitive to interface adhesion as well.

(4) Optimum processing conditions (route $5,1100^{\circ} \mathrm{C}$ ) were able to achieve not only the better mechanical strength, but also Young's modulus values from $75 \mathrm{GPa}$ (in contact with a prosthetic crown) up to $24 \mathrm{GPa}$ (in contact with cortical bone). This tendency of mechanical properties indicate that optimum PM processing can help to reach the better mechanical balance between suitable yield strength and a reasonably low Young's modulus.

\section{Acknowledgments}

This work was supported by the Ministerio de Economía y Competitividad (MINECO), Spain, through the project Ref. MAT201020855. In addition, the authors wish to thank I. Rube and M. C. Martín for their collaboration in some of the experimental tasks of this paper.

\section{References}

[1] Thieme M, Wieters K-P, Bergner F, Scharnweber D, Worch H, Ndop J, et al. Titanium powder sintering for preparation of a porous functionally graded material destined for orthopaedic implants. J Mater Sci - Mater Med 2001;12:225-31.

[2] Crowninshield RD, Rosenberg AG, Sporer SM. Changing demographics of patients with total joint replacement. Clin Orthop Relat Res 2006;443: 266-72.

[3] Brunette D, Tengvall P, Textor M, Thomsen P. Titanium in medicine: materials science, surface science, engineering, biological responses and medical applications. Berlin: Springer; 2001.

[4] Qazi JI, Rack HJ, Marquardt B. High-strength metastable beta-titanium alloys for biomedical applications. JOM 2004;56:49-51.

[5] Staiger MP, Pietak AM, Huadmai J, Dias G. Magnesium and its alloys as orthopedic biomaterials: a review. Biomaterials 2006;27:1728-34.

[6] Gibson L, Ashby M. Cellular solids: structure and properties. 2nd ed. Cambridge: Cambridge University Press; 1997.

[7] Banhart J. Manufacture, characterization and application of cellular metals and metal foams. Prog Mater Sci 2001;46:559-632.

[8] Singh R, Lee PD, Dashwood RJ, Lindey TC. Titanium foams for biomedical applications: a review. Mater Technol 2010;25:127-36.

[9] Parthasarathy J, Starly B, Raman S, Christensen A. Mechanical evaluation of porous titanium (TiAl6V4) structures with electron beam melting (EBM). J Mech Behav Biomed Mater 2010;3:249-59.

[10] Oppenheimer SM, Dunand DC. Porous NiTi by creep expansion of argon-filled pores. Mater Sci Eng, A 2009;523:70-6.

[11] Chino Y, Dunand DC. Directionally freeze-cast titanium foam with aligned, elongated pores. Acta Mater 2008;56:105-13.

[12] Ryan GE, Pandit AS, Apatsidis DP. Porous titanium scaffolds fabricated using a rapid prototyping and powder metallurgy technique. Biomaterials 2008;29: 3625-35.

[13] Wiria FE, Shyan JY, Lim PN, Wen FGC, Yeo JF, Cao T. Printing of titanium implant prototype. Mater Des 2013;49:S101-5.

[14] Krishna BV, Bose S, Bandyopadhyay A. Low stiffness porous Ti structures for load-bearing implants. Acta Biomater 2007;3:997-1006.

[15] An YB, Oh NH, Chun YW, Kim YH, Kim DK, Park JS, et al. Mechanical properties of environmental-electro-discharge-sintered porous Ti implants. Mater Lett 2005;59:2178-82.

[16] Orrù R, Licheri R, Locci AM, Cincotti A. Cao G. Consolidation/synthesis of materials by electric current activated/assisted sintering. Mater Sci Eng, R: Reports 2009;63:127-287.

[17] Oh IH, Nomura N, Masahashi N, Hanada S. Mechanical properties of porous titanium compacts prepared by powder sintering. Scripta Mater 2003;49: 1197-202.

[18] Naito Y, Bae J, Tomotake Y, Hamada K, Asaoka K, Ichikawa T. Formability and mechanical properties of porous titanium produced by a moldless process. J Biomed Mater Res Part B - Appl Biomater 2013;101B:1090-4.

[19] Wen CE, Mabuchi M, Yamada Y, Shimojima K, Chino Y, Asahina T. Processing of biocompatible porous Ti and Mg. Scripta Mater 2001;45:1147-53.

[20] Jha N, Mondal DP, Majumdar JD, Badkul A, Jha AK, Khare AK. Highly porous open cell Ti-foam using $\mathrm{NaCl}$ as temporary space holder through powder metallurgy route. Mater Des 2013;47:810-9.

[21] Li BQ, Wang CY, Lu X. Effect of the pore structure on the compressive property of porous Ti produce by powder metallurgy technique. Mater Des 2013; 50:613-9.

[22] Traini T, Mangano C, Sammons RL, Mangano F, Macchi A, Piattelli A. Direct laser metal sintering as a new approach to fabrication of an isoelastic functionally graded material for manufacture of porous titanium dental implants. Dent Mater 2008;24:1525-33.

[23] Currey J. Handbook of biomaterials properties. In: Black JH editor. London: Garth; 1998.

[24] Miao X, Sun D. Graded/Gradient Porous Biomater Mater 2010;3:26-47.

[25] Oh IH, Segawa H, Nomura N, Hanada S. Microstructures and mechanical properties of porosity-graded pure titanium compacts. Mater Trans 2003; 44:657-60.

[26] Lee JW, Lee JS, Kim MG. Fabrication of porous titanium with directional pores for biomedical applications. Mater Trans 2013:54:137-42.

[27] Laptev A, Bram M, Buchkremer HP, Stöver D. Study of production route for titanium parts combining very high porosity and complex shape. Powder Metall 2004;47:85-92.

[28] Torres Y, Pavón JJ, Nieto I, Rodríguez JA. Conventional powder metallurgy process and characterization of porous titanium for biomedical applications. Metall Mater Trans B 2011;42:891-900. 
[29] Torres Y, Lascano S, Bris J, Pavón JJ, Rodríguez JA. Development of porous titanium for biomedical applications: A comparison between loose sintering and space-holder techniques. Mater Sci Eng, C 2014;37:148-55.

[30] Collins EW. The physical metallurgy of titanium alloys. Ohio: Metals Park; 1984.

[31] Bansiddhi A, Dunand DC. Shape-memory NiTi foams produced by replication of $\mathrm{NaCl}$ space-holders. Acta Biomater 2008;4:1996-2007.

[32] Torres Y, Pavón JJ, Rodríguez JA. Processing and characterization of porous titanium for implants by using $\mathrm{NaCl}$ as space holder. J Mater Process Technol 2012;212:1061-9.
33] Torres Y, Rodríguez JA, Arias S, Echeverry M, Robledo S, Amigo V, et al Processing, characterization and biological testing of porous titanium obtained by space-holder technique. J Mater Sci 2012;47:6565-76.

[34] ASM-International. Nondestructive evaluation and quality control. 9th ed. 1989.

[35] Kikuchi M, Takahashi M, Okuno O. Elastic moduli of cast Ti-Au, Ti-Ag, and Ti-Cu alloys. Dent Mater 2006;22:641-6. 